\title{
Audit backs jailed professor's allegations
}

Quebec. Canada's largest research grantmaking agency, the Natural Sciences and Engineering Research Council (NSERC), has frozen all grants to Concordia University in Montreal after an audit report showed serious irregularities in the university's engineering and computer science faculty.

Ironically, the contents of the report as well as that of two others issued earlier this year - reinforce charges made by a former research professor in the faculty, Valery Fabrikant, who is currently serving a life sentence for murdering four of his colleagues in August 1992.

Fabrikant, who had been threatening and harassing faculty members for months before the murders, said he killed the four to draw attention to his charges of research fraud, contract irregularities, and what he claimed was an unjust denial of tenure.

Peter Morand, the president of the research council, says that in order to maintain its eligibility for future funds, the university must satisfy the council within 60 days that it has introduced mechanisms to correct the flaws that the report identifies. It must also return the misused funds.

The audit was carried out by the Montreal firm Bessner Gallay Schapira Kreisman, and revealed that research money had been put to unauthorized uses at the university for at least 20 years. It found that some faculty members, justifying their activities in the name of academic freedom, had carried out extensive freelance work.

Three engineering faculty members have had their research grants suspended and have been forced to leave the university. Seshadri Sankar will go on unpaid leave immediately before resigning on 31 December 1995. His brother Thiagas S. Sankar will take unpaid leave from July 28 until February, when he will begin early retirement. The third to leave is the former dean, M. N. $\mathrm{S}$. Swamy, who will take early retirement on 1 September, when his current sabbatical leave ends.

An earlier report on the situation surrounding Fabrikant's violence against his academic colleagues was carried out by John Scott Cowan, former vice-rector of the University of Ottawa. It sharply criticized Concordia officials for allowing Fabrikant to carry on his vendetta.

Concordia's board of governors dismissed the rector, Patrick Kenntiff, a former law professor and Quebec civil servant, as well as three other senior staff immediately after the report was released on 31 May.

\section{Correction: EMBL}

The European Molecular Biology Laboratory's nucleotide sequence data base that is being transferred to its European Bioinformatics Institute in Cambridge covers sequences from all organisms, not just mammals as stated in our issue of 7 July.
A second report, prepared by a threeperson committee chaired by Harry Arthurs, a former president of York University, compared Concordia's research culture to an automobile industry driven by quantity rather than quality. It said that "ends are sometimes used to justify means which are highly questionable", including "inappropriate authorial credit" and excessive outside work.

Fabrikant's output of 25 papers in less than four years was more than twice the average. On most of these Thiagas Sankar, the chairman of Fabrikant's department, was listed as co-author.
The NSERC has now alleged that poor administrative practices allowed elaborate schemes to be set up in which false records were maintained, and the true nature of expenditures concealed both from the research councils and other funding bodies.

The NSERC's committee on professional and scientific misconduct will now consider whether further sanctions are warranted against the individuals involved. Charles Bertrand, the university's interim rector, has denied that the university let the three professors off lightly because of its own administrative failures.

David Spurgeon

\section{'More co-ordination needed' in EU}

Schwerin, Germany. Paul Krüger, the German research minister, promised this week that Germany's presidency of the European Union (EU) will be marked by efforts to improve coordination between national and EU research programmes.

Krüger was speaking at an informal meeting of European research ministers held to mark the start of Germany's six-month presidency. Both he and the other ministers expressed in particular a desire to alter the role of the Science and Technology Research Committee (CREST), a body made up of two members from each country, and chaired by the European Commission (EC).

CREST was set up in 1974 to help promote community-wide research policy, partly by coordinating national policies with those of the European Communities. But many feel the committee has lost its original dynamism, while the recently appointed European Science and Technology Assembly has taken over much of its active advisory role.

The ministers discussed ways of improving CREST's effectiveness, for example by asking it to concentrate on longer-term EU research strategies and on the evaluation of past research policies.

Only 14 per cent of public research and development resources are spent through European-level organizations and agencies, and the EC Framework programme at present accounts for only 4 per cent. The rest of the money is provided through national programmes, which often do not cooperate with each other.

The EU research commissioner, Antonio Ruberti, says these figures show why closer coordination is essential. But coordination is a thorny problem, as it impinges on the right of national states to set their own research agendas, and conflicts with the principle of subsidiarity.

Nevertheless, there are signs that coordination is starting to enter the mentality of member states. For example, after meetings with the heads of national research councils in EU member states last month, research councils in Italy, France and Spain have presented two joint proposals to the commission concerning environmental research in the Mediterranean.

Ruberti is encouraging similar joint applications from other national research agencies, as well as the electrical and automobile industries. National research agencies will have to put forward a good proportion of the money for any participation. But Ruberti says he is prepared to provide a cash incentive - which he describes as a "wedding present" - for any coordinated project.

Other "wedding presents" are also under discussion. The seven leading aviation research establishments in Europe have combined to form an association which plans to develop common policy on cooperation among themselves and with the commission, and to share large-scale experimental and test facilities.

Krüger proposes that the commission should support this initiative by giving preferential support from its research programmes to research projects coordinated by the association.

The research ministers also discussed two other issues that have been concerning European researchers, namely why they should get such different rates of pay if they receive EC grants to work in other countries, and why applying for a grant is such a confusing and laborious task.

The EC's Human Capital and Mobility programme, which offers fellowships to young researchers to work in a different EU country, has been a major problem since its introduction early last year (see Nature 361, 196; 1993).

The commission has set up a working group to try to solve this problem. But its task is likely to be difficult. "Ideally I would like to see no tax at all on these fellowships which should go entirely to research activities," says Ruberti.

Alison Abbott 